\title{
CONSERVACIÓN DE LA SALUD DEL CUERPO COMO ESTRATEGIA DE VIGILANCIA Y CONTROL DEL DERECHO EN LO CONCERNIENTE A LO HIGIÉNICO Y SANITARIO DESDE LAS REFORMAS BORBÓNICAS
}

\author{
Ana Cecilia Becerra Pabón* \\ Wilmar Peña Collazos**
}

Fecha de Recepción: 29 de Octubre de 2010

Fecha de Aceptación: 1 de diciembre de 2010

Artículo Reflexión.

\begin{abstract}
Resumen
Se presenta este ensayo como una indagación en el proceso y evolución del arte de la medicina y los orígenes de la enfermería dentro de un período que cubre el final del gobierno bajo el dominio de los Austrias a los Borbones. Así mismo, interpreta el arte liberal de gobernar con sus leyes y regulaciones de control, coacción y coerción que van a constituir la contrapartida y el contrapeso de las libertades durante este período. Esas grandes técnicas disciplinarias que se hacen cargo del comportamiento de los individuos, de los cuerpos y su salud, diariamente y hasta en lo más fino de los detalles son contemporáneas en su desarrollo y evolución, en su esparcimiento en la sociedad. Si bien es cierto que el mundo contemporáneo o el mundo moderno desde el siglo XVIII, fue intervenido por cierta cantidad de fenómenos que podemos llamar críticos, se suman a la crisis del liberalismo en íntima conexión con la crisis del derecho y la economía del capitalismo. Se trata de la crisis del dispositivo general de gubernamentalidad, la que - de acuerdo con Michel Foucault - va a dar origen al nacimiento de la biopolítica.
\end{abstract}

\section{Palabras clave}

Biopolítica, biopoder, liberalismo, medicina, enfermería, botánica, control, gubernamentalidad, salud, técnicas disciplinarias, agenciamiento, vigilancia, probanzas de sangre.

* Docente - Investigadora Universidad Santiago de Cali, y Universidad Libre (Cali). Pregrado en Enfermería Fundación Universitaria Ciencias de la Salud, Especialización en Enfermería materno perinatal Universidad del Valle, especialización en docencia universitaria Universidad Militar Nueva Granada, C. Ph.D en Educación con énfasis en pedagogía Universidad del Cauca. anabecerra74@hotmail.com

** Docente T.C. Universidad Militar Nueva Granada - Departamento de Humanidades. Licenciado en Filosofía de la Universidad Javeriana. Especialización en Artes y Folclor - Universidad El Bosque - Escuela Colombiana de Medicina. Especialización Docencia Universitaria - Universidad El Bosque - Escuela Colombiana de Medicina. Especialización Planificación del desarrollo regional y municipal. Maestría en filosofía latinoamericana Universidad Santo Tomás De Aquino - Sede Bogotá. Maestría en Historia - Universidad Nacional De Colombia - Sede Bogotá. C- Ph.D en Filosofía Pontificia Universidad Javeriana.wilmar.peña@unimilitar.edu.co; pc.wilmar@gmail.com 


\title{
PHYSICAL HEALTH CONSERVATION AS A SURVEILLANCE AND LAW CONTROL STRATEGY CONCERNING HYGIENE AND SANITATION ON THE BOURBON REFORMS
}

\begin{abstract}
This essay is presented as an inquiry into the process and evolution of medical art and the origin of nursing in a period between the end of the rule of the Austrians and the rule of the Bourbons. Also, It seeks to interpret the liberal art of ruling within a closed set of laws, control regulations, compulsion and coercion that will become the counterpart of freedoms during this period.
\end{abstract}

Those great disciplinary techniques that take care of the behavior of the individuals, the bodies end their health, daily, to the more minute details, are contemporary in their development and evolution, in its spreading trough society.

The contemporary or modern world since the fifteenth century was influenced by a certain amount phenomena that we could refer of as critical, added to the crisis of liberalism in close connection with crisis in law and capitalist economy.

This is a crisis of the general power device, that - according to Michel Foucault- will give birth to biopolitics.

\section{Keywords}

Biopolitics, biopower, liberalism, medicine, nursing, botany, control, government, health, disciplinary techniques, surveillance, blood proofs.

\section{CONSERVAÇÃO DA SAÚDE DO CORPO COMO ESTRATÉGIA DE VIGILÂNCIA E CONTROLE DO DIREITO NO QUE CONCERNE AO HIGIÊNICO E SANITÁRIO DESDE AS REFORMAS BOURBÔNICAS}

\section{Resumo}

Este ensaio é apresentado como uma indagação no processo e evolução da arte da medicina $e$ as origens da enfermagem dentro de um período que cobre o final do governo sob domínio dos Áustrias até os Bourbons. Da mesma forma, interpreta a arte liberal de governar com suas leis e regulamentos de controle, coação e coerção que irão constituir a contrapartida e o contrapeso das liberdades durante este período. Essas grandes técnicas disciplinares que se encarregam do comportamento dos indivíduos, dos corpos e sua saúde, diariamente e até o mínimo detalhe, são contemporâneas em seu desenvolvimento e evolução, em sua dispersão na sociedade. Ainda que seja certo que o mundo contemporâneo, ou o mundo moderno a partir do século XVIII, tenha sofrido a intervenção de um certo número de fenômenos que podemos chamar críticos, eles se somam à crise do liberalismo, em íntima conexão com a crise do direito e a economia do capitalismo. Trata-se da crise do dispositivo geral de governabilidade, que - de acordo com Michel Foucault - vai dar origem ao nascimento da biopolítica.

\section{Palavras-chave}

Biopolítica, biopoder, liberalismo, medicina, enfermagem, botânica, controle, governabilidade, saúde, técnicas disciplinares, "agenciamento", vigilância, provas de sangue. 
Debemos analizar la manera en la cual los fenómenos, las técnicas, los procedimientos de poder funcionan en los niveles más bajos; mostrar cómo estos procedimientos se trasladan, se extienden, se modifican, pero sobre todo mostrar cómo fenómenos más globales los invisten y se los anexionan y cómo poderes más generales o poderes económicos pueden insertarse en el juego de estas tecnologías de poder relativamente autónomas $e$ infinitesimales (FOUCAULT: 1992: 40)

\section{A MODO DE INTRODUCCIÓN}

\section{Del dispositivo biojurídico de la proban- za de limpieza de sangre a los controles sanitarios}

El imperio español generó un discurso biopolítico $^{1}$ con una carga afectiva de dominación muy fuerte a partir del sistema impuesto en el Nuevo Mundo, reconocido como "limpieza de sangre" ${ }^{2}$ el cual consistía en una probanza o demostración con testigos reconocidos por $\mathrm{su}$ fe y demostraban ser "cristianos viejos" ante la corona española, quienes daban sus declaraciones firmadas ante un escribano público y manifestaban abiertamente dar fe de la calidad de raza del joven dispuesto a emprender un proceso de inserción en el mundo productivo. Y normalmente cinco testigos debían dar fe del conocimiento del solicitante, de su buen nombre y de su pureza de sangre, además de no poseer

1 Por "biopolítica" se tendría que entender la manera en que, a partir del siglo XVIII, se buscó racionalizar los problemas planteados a la práctica gubernamental por los fenómenos propios de un conjunto de ciudadanos en cuanto población: salud, higiene, natalidad, longevidad, morbilidad, raza, resistencias somáticas.

2 Desde el inicio del descubrimiento de América comenzaron a establecerse distintas disposiciones que impidieron en primer término a los judíos y moros y a sus descendientes, asumir posiciones importantes en el Nuevo Continente. Más aún las restricciones no se hicieron esperar, se impartieron muchos edictos en las Leyes de Indias que impedían a los conversos, a sus descendientes y a los reconciliados por la Inquisición, trasladarse a América. antecedentes con la Inquisición, tanto él como su familia, por varias generaciones, llegando en algunos casos hasta siete.

Más aún, los Estatutos de Limpieza de Sangre, los requerimientos y listados de este proceso, que reposan en los archivos de los colegios y universidades de mayor tradición (Colegio Mayor de San Bartolomé y Colegio de Nuestra Señora del Rosario), moldearon el espíritu del pueblo español en el sentido de otorgarle importancia suprema a la genealogía, a los linajes, a la noble cuna, al matrimonio católico y al nacimiento de las personas. El exagerado aprecio por los títulos de nobleza, los blasones y escudos de armas, son demostración de este dominio. Más aún, esta fue la forma de ejercer el control sobre la población. Se generó un connotado desprecio por las personas que no los poseyeran y eran considerados inferiores y por medio de los Estatutos se negaba todo tipo de honores, la capacidad de ocupar cargos públicos, de ejercer algunas artes y oficios y la posibilidad de cualquier ascenso social en una institución.

Fue así como se configuró un imaginario aristocrático de la españoleidad, anclado en el habitus del mundo criollo, lo cual constituyó la base ideológica sobre la que un grupo privilegiado legitimó su dominio sobre todas las castas, descendientes de negros, indios, gitanos, judíos, moros o berberiscos. El discurso ilustrado de los Borbones pronto se convirtió en una amenaza contra el poder de la elite criolla que defendió el predominio de la raza blanca del español. Pero en realidad, buena parte de la elite de criollos ilustrados consideró las reformas borbónicas como un complemento del discurso colonial de la pureza de sangre que defendía el postulado fisiocrático sobre la defensa de las tierras ${ }^{3}$, desde "la pretensión ilustrada de

Las doctrinas de los fisiócratas, que literalmente se refería a la administración de la Physis o naturaleza, pretende fundarse bajo leyes naturales mecanicistas, que le dan preponderancia a la agricultura como fuente de las riquezas de la Nación. Los fisiócratas y terratenientes franceses habían encontrado en la agricultura un medio para regenerar a Francia. Con el 
colocarse como observadores imparciales del mundo- lo que aquí (dice Santiago Castro) he denominado la "hybris del punto cero"-, será para ellos el motivo perfecto para fortalecer su imaginario habitual de dominio sobre las castas"(CASTRO, 2005 p.141).

Uno de los requisitos para entrar a la Universidad y para poder ser examinado como doctor consistía en pasar la prueba de "probanza de sangre", lo cual significaba estar libre de ancestros musulmanes, judíos o berberiscos e implicaba que tanto mulatos, como negros, indios y raizales, así como todos aquellos que hubieran tenido vínculos con la esclavitud, se sumaban a los que no tenían derecho a estudiar y recibir títulos. La medicina era una carrera que se había envilecido desde siglos pasados por la influencia del neoplatonismo que proclamaba al cuerpo como la cárcel del alma y tanto las pasiones, las emociones y deseos de la carne fueron envilecidos. Pero la medicina fue alcanzando un estatus en la medida en que se privilegió el cuidado como fundamento de salvación. Así pues, la historia natural, la medicina y la astronomía pronto se convirtieron en la profesión de hombres no europeos. El Sabio Mutis y otros científicos enseñaron historia natural a los americanos y realizaron prácticas de higiene, salud preventiva e intervención curativa; además, fundaron instituciones como jardines botánicos, museos, observatorios astronómicos y cátedras universitarias. Así se convirtieron en satélites de un proyecto de ordenamiento territorial bajo el control de una nueva élite de hombres "civilizados" nacidos en América, pero de sangre europea.

El control estadístico para la vigilancia del restablecimiento de la salud física fue parte fundamental del proyecto de reformas borbónicas de racionalizar la estructura económica, productiva y administrativa del imperio español en el Nuevo Mundo. Fue en manos de los

apoyo de los savants, protegidos del Jardin du Roi, se apropiaron de las teorías económicas que basaron la riqueza del Estado en el cultivo de las tierras (...). criollos ilustrados como la ciencia moderna y en particular las ciencias de la salud sirvieron como instrumento de consolidación de las fronteras étnicas que aseguraban su dominio en el espacio social de un Estado liberal que se abría paso en la constitución de una propuesta política social ${ }^{4}$. El hospital y en general toda la estructura de salud durante el siglo XIX, fueron concebidos y diseñados idealmente como máquinas de guerra, o mejor aún como "máquinas de vigilancia" (al decirlo con M. Foucault) ${ }^{5}$ para controlar la salud, la curación y el retorno de los individuos a la vida productiva, laboral; su objetivo primordial fue contabilizar a todos los enfermos, llevar estadísticas de los que se podían recuperar, dejar morir a los que no tenían otra opción y devolverle pronto las facultades corporales a los más aptos para continuar sirviendo a la sociedad en las transacciones de la vida laboral.

Tanto el sexo como la raza funcionaron como eje articulador de las dos direcciones en las que se desplegaron del biopoder, como son la disciplina y la biopolítica. Cada una de las cuatro grandes políticas del sexo que se han desarrollado en la modernidad ha sido una manera de componer las técnicas disciplinarias del individuo con los procedimientos reguladores de la población. Dos de ellas se han apoyado en la problemática de la regulación de las poblaciones (tales como el tema de la descendencia y de la salud colectiva) y han producido efectos en el nivel de la disciplina: la sexualización de la infancia y la histerización del cuerpo de la mujer. Las otras dos, inversamente, se apoyan en las disciplinas y obtienen efectos en el nivel de la población: control de los nacimientos y psiquiatrización

$4 \quad$ No se puede disociar el nacimiento de la biopolítica del cuadro de racionalidad política dentro del cual surgió, es decir, del liberalismo.

5 La formación del biopoder, según Foucault, puede ser abordada a partir de las teorías del derecho y de la teoría política. Así pues, los juristas del siglo XVII y del XVIII han planteado la cuestión del derecho de vida y de muerte, la relación entre la preservación de la vida, el contrato que da origen a la sociedad y a la soberanía o en el nivel de los mecanismos, de las técnicas y de las tecnologías del poder. Foucault se sitúa en esta última perspectiva. 
de las perversiones. Por otra parte, la sangre y sexualidad fueron los nuevos procedimientos del poder puestos en funcionamiento en el siglo XIX y que, de acuerdo con Michel Foucault, han hecho que nuestras sociedades pasaran de una sociedad simbólica de la sangre a una sociedad analítica de la sexualidad. Es decir, lo que está del lado de la ley, de la muerte, de la transgresión, de lo simbólico y de la soberanía, fue la sangre y la manera como se controló la sociedad fue a partir de su raza y de su sexo. Así pues, la sexualidad está del lado de la norma, del saber, de la vida, del sentido de las regulaciones.

Los principios de una sociedad liberal bajo la ley y la norma, constituyó una sociedad normalizadora. Así, el principio 'poder matar para poder vivir', que sostenía la táctica de los combates, se convirtió -según Foucault- en principio de estrategia de los Estados; pero la existencia en cuestión no es aquélla, jurídica, de la soberanía, sino aquélla, biológica, de una población. Por ello la importancia creciente de la norma y, consecuentemente, de la normalidad, en detrimento del sistema jurídico de la ley. La norma se aplica tanto a un cuerpo que se quiere disciplinar como a una población que se quiere regularizar. La sociedad de normalización no es una sociedad disciplinaria generalizada, cuyas instituciones disciplinarias habrían colonizado y finalmente recubierto todo el espacio. Más aún, la sociedad de normalización es una sociedad en la que se cruzan la norma de la disciplina y la norma de la regulación. La sexualidad es un ejemplo mayor de este cruce ortogonal de disciplina y biopolítica. En ese sentido, una sociedad normalizadora es el efecto histórico de una tecnología de poder centrada sobre la vida. Esta forma del poder, a la vez individualizante y totalizante, es para Foucault la característica fundamental del poder moderno.

Antes del siglo XVIII los hospitales eran considerados sitios para morir, no para curar. Al respecto Foucault menciona: "El personal que trabajaba en el hospital no estaba destinado a curar al enfermo sino a conseguir su propia salvación". (FOUCAULT: 1990: 156) Quien curaba lo hacía con el interés de poder salvar su propia alma; en tal momento los religiosos eran los que habitaban y ejercían la labor de enfermería, más como una vocación religiosa que aseguraría más en sentido apologético la salvación de sus propias almas, que el predominio de una labor de carácter profesional.

Al normalizar las visitas del médico a estos pacientes hospitalizados, se empezó a cambiar el paradigma y el poder pasó de manos de los religiosos a manos de los médicos que con un saber científico de por medio, decidían las conductas y los tratamientos de los pacientes; los cuales ya no iban al hospital únicamente a morir, sino tenían la alternativa de la curación.

Este ritual codificado de la visita, que señala la implantación del poder médico se encuentra en los reglamentos de hospitales del siglo XVIII, en donde se indica dónde debe colocarse cada persona, que la presencia del médico debe ser anunciada con una campanilla, que la enfermera debe estar en la puerta con un cuaderno en la mano y acompañar al médico cuando entre, etc. (FOUCAULT: 1990: 169)

La historia de la educación en enfermería empezó con Florence Nightingale ${ }^{6}$ (1860 Escuela de Enfermería del Hospital Santo Tomás, Londres). Ella misma sostenía que la enfermería era un llamado o vocación y los valores de este ideal tendían a inhibir el desarrollo de puntos de vista profesionales. (SHYOCK: 1959) Fue ella quien hizo las

6 Florence Nightingale se considera la precursora de la enfermería. Su nombre se popularizó gracias a sus aportes en la guerra de Crimea (Turquía), ella se dedicó a la atención de muchos heridos, incluso de enemigos. Desarrolló un propósito o modelo de enfermería que se basa en brindar un medio saludable que rodee al paciente. Los componentes del medio o entorno, serán controlados desde la función de la enfermería, tales como: 1) Ventilación equilibrada, 2) Luz adecuada, 3) Calor suficiente, 4) Control de efluvios (enfermedades de aire, olores), 5) Control de ruidos. Lo importante es el entorno que rodea al paciente, la enfermería debe propiciar y proporcionar un entorno adecuado o saludable para permitir o dejar actuar las leyes de la naturaleza. 
primeras contribuciones a la teorización de la enfermería, identificando a la persona y a su entorno ${ }^{7}$ como base y mantenimiento de la salud. A su vez, Marriner no establece una diferenciación precisa entre los aspectos físico, emocional y social, pues asume que todos estos aspectos están incluidos y relacionados mutuamente para explicar en su conjunto la profesionalización de la teoría, lo cual no fue producto del azar. (MARRINER: 1994: 75)

Florence Nightingale afirmaba que "la enfermería es la más bella de las artes"; ella estableció las bases de la enfermería moderna con su forma de tratamiento de los enfermos y heridos durante la guerra de Crimea (18531856). Una vez concluida la guerra y ya de regreso a Londres, fundó allí la Escuela y Hogar para Enfermeras, con el fin de capacitar a las mujeres que habrían de servir a los enfermos en esta noble labor. La enfermería no es la técnica en el cuidado, sino un proceso que incorpora el desarrollo del alma, la mente y la imaginación, pues implica poner todos los sentidos, la mente, la razón y todo el ser para ser creativos con una profesión que evoluciona, al tiempo que evoluciona el ser humano. La esencia de la enfermería reside en la imaginación para ser creativos y reinventar la enfermería como función humana y social, en ella se asume el espíritu sensible y la comprensión inteligente, que constituyen el fundamento real de los cuidados de enfermería más eficaces para propiciar la sanación física y el equilibrio.

7 El concepto de entorno no aparece como tal en sus escritos, pero los conceptos como ventilación, luz, calor, limpieza y ruido están como idea principal en la influencia de la salud de las personas.

8 Las artes se subdividían en Liberales y Mecánicas. Las primeras se referían al ejercicio del entendimiento y el espíritu bajo determinadas reglas y bajo el rigor de un aprendizaje controlado por un maestro; las segundas, se referían a artes que involucraban más el predominio del cuerpo bajo la mecánica de un aprendizaje que requería destreza más física que mental. En un comienzo el arte de curar se asignaba a sacamuelas, barberos y sangradores, pero con el correr de los siglos la profesión se fue depurando hasta alcanzar el profesionalismo en la universidad.
Durante este período la enfermería asumió una fuerte tendencia de doble vía: la religiosa y la maternal femenina. Durante el siglo XVII las fundaciones sanitarias a cargo de órdenes y grupos religiosos se establecieron con constituciones propias en hospitales, como centros de caridad y cuidado de ancianos o minusválidos, con una función de carácter religioso y con una orientación propiamente filantrópica. Allí se procuraba que los barberos desempeñaran bien su oficio (sajar, sangrar o "echar ventosas", sacar muelas y "echar" sanguijuelas). Así mismo, no todo el mundo podía ser barbero puesto que para desempeñarse laboralmente se debía aprender previamente el oficio y presentar un examen, estipulado con rigor por ley para este gremio. En la segunda vía, habría que advertir que la enfermería se desarrolló bajo el sentido de la tutela o de los cuidados, lo cual se podría denominar tendencia maternal doméstica, por ser la mujer en cada hogar la encargada de este aspecto de la vida; el objetivo prioritario de atención de la mujer cuidadora es el mantenimiento de la vida frente a las condiciones adversas del medio. En torno a cada mujer en la familia se entrelazan y elaboran las prácticas rituales que tienden a asegurar la vida, su promoción y su continuidad; la mujer utiliza elementos que son parte de esa misma vida natural, como el agua para la higiene, las pieles para el abrigo, las plantas y el aceite para la alimentación y las manos, elemento muy importante de contacto maternal, para transmitir bienestar.

Fueron las monjas, destinadas a esta labor de cuidado, quienes desempeñaron una labor pionera de la enfermería asumida como una labor evangélica, pues no se desligaba la salvación del cuerpo de la salvación del alma, así como tampoco se podía deslindar el sentido del pecado de la enfermedad corporal. En consecuencia, los cuidados van encaminados a ese mantenimiento de la vida a través de la promoción de la higiene, la adecuada alimentación, el vestido y, en general, las buenas costumbres de rezar, asumir un control moral y todas las medidas que hacen la vida más agradable, algunas de las cuales se han dado en llamar en nuestros días cuidados básicos. 
La enfermería en tanto cuidado de la salud, preservación y defensa del paciente para el mantenimiento de la vida saludable y equilibrada, recayó en la mujer y en el sanador. Sobre todo en la mujer cuidadora, puesto que el protagonismo de los cuidados fue adjudicado a las mujeres, ellas mujeres devotas guiadas por un fuerte grupo de monjas que se enlistaron como seguidoras de Cristo para ayudarle a sanar los enfermos del alma y el cuerpo. Son las mujeres quienes han asumido y desempeñado en cada familia las prácticas encaminadas al mantenimiento de la vida, a través de elementos naturales como la higiene, el vestido, la alimentación y todos aquellos cuidados que favorecen el bienestar. La práctica de este tipo de cuidados se entremezclaban con actividades rituales para la protección, la promoción y la continuación de la vida. Los elementos empleados por la cuidadora formaban parte de la propia naturaleza; así pues, había un elemento para cada función: para la higiene, el agua; para el abrigo, las pieles; para la alimentación, las plantas, y para transmitir bienestar afectivo, el contacto físico a través de la caricia y la ternura femenina.

Durante el período de los Austrias, el cristianismo introdujo en la propuesta de salud un ingrediente: la caridad, en cuanto en ella se proclamaba el deber de atender al enfermo "solo por amor", el dinero no era tenido en cuenta, la asistencia médica y los cuidados de recuperación eran totalmente gratuitos. Además, los cuidados para el proceso de recuperación lo asumían con infinita paciencia mujeres que dedicaban todo su tiempo a los enfermos por devoción a Cristo y con el ánimo de su propia salvación. Así, la filantropía se asumió como "amor al hombre", bajo el propósito de caridad operativa para con el paciente necesitado del perdón y de la sanación, conferida y asumida por el mismo Cristo. La caridad médica se evidenciaba en la creación de hospitales con recursos de donativos y de caridad.

\section{Cambios sustanciales en la administración de la salud: de los Austrias a los Borbones}

Desde el período que dominaron los Austrias, el hospital era concebido como una institución de caridad o socorro, que administraban los curas y las monjas para brindar "hospital-idad" a los menesterosos, con el objeto de brindarles por igual asistencia espiritual y salud a los enfermos y desvalidos. En los hospitales era menester encontrar no sólo enfermos, sino ancianos, niños, viudas, inválidos y personas sin trabajo, todos aquellos que por incapacidad productiva o física, no podían proveer su propio sustento (QUEVEDO: 1993: 51). Fue así como los hospitales, al igual que los colegios y lazaretos, tuvieron una manifiesta finalidad evangélica y apologética, pues mediante la caridad que allí se administraba se defendían los principios de la fe y se afianzaba la adhesión a la santa madre iglesia.

En los comienzos no había un sistema público de salud, propiamente la asistencia pública y rural carecía de base o fundamentos, pues la higiene pública era mínima o no existía, todo el mundo botaba los desperdicios en las fuentes de agua, no había sanitarios públicos y tanto ríos como acequias eran utilizadas como botadero de toda clase de residuos orgánicos; en fin de cuentas, no había disposiciones de control que establecieran los principios del cuidado y la higiene. A partir de Carlos III se dispuso algún avance en el control de la sanidad con disposiciones y leyes sobre establecimientos de desagües, la prohibición de arrojar desperdicios por las ventanas a las vías públicas o abandonarlos en plazas públicas, caminos vecinales y mercados; también, el rey dispuso ordenamientos para la iluminación de plazas, barrios y calles que antes permanecían en penumbras o apenas eran iluminados tenuemente por la luz de los serenos. Así mismo, intentó reducir la embriaguez y ordenó el embaldosamiento alrededor de las casas y algunos solares importantes.

Antes del siglo XVIII, la medicina europea había tenido un impacto más bien insignificante en la colonia, y los curanderos nativos "charlatanes", "hierbateros" o "parteras" constituían los agentes de salud más importantes de la población americana compuesta por indígenas, mestizos 
y españoles. Con el siglo XVIII, la medicina ilustrada comenzaría a dominar en las ciudades coloniales, pero las prácticas populares y aborígenes seguirían siendo muy importantes, particularmente en el campo. La medicina y la farmacia constituyeron un interés primordial del gobierno español durante el período de los Borbones. (NIETO: 2000: 141).

Con la llegada del cristianismo y sus valores morales y patriarcales, los cuidados concebidos como la ayuda al prójimo, pasaron a ser un instrumento de salvación y el ingreso seguro para la vida eterna. Esta idea de servicio al prójimo y camino para la santidad, llevó a muchos cristianos, especialmente mujeres a dedicar su vida al cuidado de los pobres y enfermos. Así, "los cuidados de Enfermería" se institucionalizan basándose en un "concepto de ayuda" que podríamos denominar "vocacional-cristiano-caritativo", en el que las necesidades humanas espirituales se anteponen a las necesidades físicas, psíquicas y sociales; (HERNÁNDEZ: 1995: 78) es en este momento cuando la mujer asocia sus cuidados con santidad y humildad y, entonces, surgen asociaciones femeninas religiosas cuya principal motivación era el cuidado y entrega al prójimo por vocación y amor a Cristo. Tal articulación con la religión marcó una pauta muy importante en la concepción del cuidado, ya que al estar desempeñado por religiosas, enmarcaba no sólo una vocación sino una actitud de castidad, pobreza y obediencia, lo cual produjo desde entonces y hasta la actualidad una jerarquización de roles con el resto del equipo de salud y una marcada devaluación salarial. Los cuidados de enfermería, desde su perspectiva "caritativa" no podían continuar la dinámica hacia la constitución de gremio, por poseer una dimensión exclusivamente espiritual, sin connotaciones de aprendizaje, calidad y salarios. (HERNÁNDEZ: 1995: 108)

Las prácticas de cuidado de la salud en América Latina y en Colombia, estaban asociadas a las mujeres de las comunidades. Por medio de la medicina popular, la magia y la hechicería, eran las dueñas del conocimiento y de la medicina tradicional; hechiceras, brujas y comadronas se ocupaban de preparar bebedizos, hacer y aplicar emplastos, atendían los partos y las afecciones femeninas, entre otras actividades. Con la llegada de los españoles, este rol, ejercido principalmente por mujeres, fue rechazado $y$ atacado por el cristianismo, ya que el estilo de mujer nativa indoamericana se alejaba de la concepción de mujer sumisa y silenciosa que suponía el modelo de María Madre de Dios.

Las mujeres generaron fuerte influjo en la historia de la salud pública en Colombia. Por ejemplo, el oficio de las parteras fue una de las prácticas sociales más reconocidas y difundidas, como práctica médica aceptada en diferentes estratos sociales. Con la idea de la creación de institutos de formación en enfermería a finales del siglo XIX se generó un distanciamiento entre los estudios de obstetricia y las tradicionales prácticas de las parteras, que por lo general eran mujeres adultas, respetadas en su oficio; a ellas se les restringió su labor en algunos sectores de la sociedad. Por otra parte, en las instituciones hospitalarias también hubo un importante movimiento de mujeres que se desempeñaron como organizadoras de brigadas de salud $e$ higiene y como enfermeras, auxiliares que estaban al pie de los enfermos para suministrarles las medicinas y hacer curaciones; pero este fue un oficio que se impartió con absoluta informalidad. Existían propuestas de parte de un grupo médico a finales del siglo XIX (1897) y principios del siglo $\mathrm{XX}$, consistentes en la formación de comadronas y enfermeras. Fue en la Universidad de Cartagena en 1903, cuando de forma empírica se iniciaron los primeros procesos de formación de las enfermeras, seguida por la Escuela de Enfermeras del Hospital Santa Clara en Bogotá en 1924.

Para el año de 1920, la medicina en el mundo entero había experimentado una serie de cambios debido a las experiencias vividas durante la primera guerra mundial. Se presentaron desarrollos tecnológicos para el diagnóstico, el trata- 
miento y la rehabilitación: los Rayos $X$, las prótesis y la cirugía reparadora. (CASTRILLÓN: 1985: 132)

Con la introducción de las Reformas Borbónicas las instituciones paraestatales administradas por órdenes religiosas, como hospitales, lazaretos y colegios, les quitó el privilegio a los señores curas de continuar controlando, sin la vigilancia del gobierno central, estas instituciones; fue necesario darle el poder pleno al Estado, como único administrador de la vida, la salud y la muerte de los ciudadanos. Es decir,

La política borbona ya no parte de Dios como garante de un orden cósmico eterno, sino de la actividad humana (el trabajo productivo) como único medio para ordenar la naturaleza y someterla a los dictados inmanentes de la razón. La enfermedad y la pobreza dejan de ser un destino que se acepta con resignación, para ser vistas ahora como disfunciones que pueden ser domesticadas por la racionalidad científico-técnica. Esto explica por qué razón el Estado Borbón intentó quitar a la iglesia el control sobre la dispensación del sentido de la salud y la enfermedad. Tales fenómenos debían recibir ahora una nueva significación legitimada por el Estado absolutista y su organum cognitivo: la ciencia moderna. (CASTRO: 2004: 146)

En esta época de las Reformas Borbónicas con la introducción de nuevos inventos y bajo el impulso del desarrollo tecnológico propio de la Revolución Industrial, se incorporaron elementos fundamentales que propiciaron elevadas repercusiones para la salud, así mismo las primeras técnicas estadísticas y matemáticas sirvieron para codificar y estratificar las ciudades de acuerdo con la incidencia de las enfermedades, la morbilidad y las tasas de natalidad y, también el recurso de mano de obra útil para la producción. Frente a la proliferación de las enfermedades se generó una gran Revolución en la Salud, por medio de los adelantos científicos de la revolución científica y posterior revolución microbiológica ${ }^{9}$. En este sentido, fue propiamente con las Reformas Borbónicas como se inició la configuración del Sistema de salud en Colombia ${ }^{10}$.

Así pues, el cambio fue no sólo cuantitativo sino cualitativo, se dio el paso de una "visión inmanente" y geocéntrica de la salud y la enfermedad, a una visión científica y antropocéntrica, se dio el paso de una representación teológica a una representación económica de la salud y la enfermedad, con lo cual la reforma de la política hospitalaria de los Borbones proporcionó un nuevo concepto de las ciencias médicas, ya que éstas al modernizarse contribuían con la recuperación de la fuerza laboral disponible $y$, por consiguiente, con la producción de la riqueza. Es decir, la enfermedad dejó de ser un problema del orden religioso y pasó a concebirse prioritariamente como un problema de cálculo económico, de productividad de la Nación, lo cual se direcciona con el derecho positivo. De una visión de las epidemias ${ }^{11}$ donde se concebía que los neogranadinos deberían más bien arrepentirse para evitar el contagio, se pasó a una concepción higiénica y preventiva, con el consiguiente desarrollo del censo, la estadística y las matemáticas dentro de las ciencias de la salud.

9 Es de destacar investigadores como: Jenner con la vacuna antiviruela, Pasteur con la vacuna antirrábica, Koch descubrió el bacilo de TBC y los microbios del cólera y finalmente, Lister descubrimiento y aplicación de los primeros antisépticos.

10 El sistema de salud es una organización que pretende atender las necesidades de salud de la población, con base en dos criterios característicos como recursos, normas, leyes y políticas públicas de salud.

11 "Las diferencias entre el edicto virreinal de 1782 y el bando de 1802 con respecto al significado de la epidemia son evidentes. Las medidas para evitar el contagio ya no pasan por las rogativas públicas y el arrepentimiento individual, sino por la inspección médica y la higiene". Francisco Gil. Disertación físicomédica para la preservación de los pueblos de las viruelas. En: CASTRO-GÓMEZ, S. (2004). La hybris del punto cero: ciencia, raza e ilustración en la Nueva Granada (1750-1816). Bogotá. Colombia: Pontificia Universidad Javeriana / Instituto Pensar. p. 153 
Fue así como la erradicación de las enfermedades se convirtió, entonces durante el s. XIX, en un asunto de biopolítica.

Se iniciaron censos sistemáticos de la población en las principales ciudades, se procesó estadísticamente la información sobre enfermos terminales, intermedios y enfermos leves, todo con el fin de sistematizar el cuidado y proponer las normas adecuadas para cada nivel de gravedad; así mismo, se reorganizó administrativamente cada ciudad dependiendo de su capacidad laboral; se crearon nuevas leyes sanitarias, dirigidas más a la prevención que a la curación, con lo cual se enfatizaba en la administración de las buenas costumbres, la higiene y usos adecuados de diferentes artefactos y lugares públicos, que conllevaban a la promulgación de nuevas leyes y multas para los infractores, etc.

\section{La revolución liberal en el origen de la biopolítica}

La ruptura política con el dominio español feudal y la consiguiente introducción de las ideas radicales del liberalismo en Colombia implicaron cambios en los conceptos de salud, sanidad, higiene, enfermedad y muerte, pues se abandonaron las ideas religiosas que regían los comportamientos frente al conflicto de las enfermedades y se implementaron ideas más ligadas a las explicaciones científicas de la salud. Ésta dejó de asumirse como consecuencia de un don divino y la enfermedad dejó de ser considerada como consecuencia del castigo por los pecados cometidos, sino como efecto del abandono en las medidas sanitarias o por descuido en el cuidado de sí. Así pues, se tomaron medidas para expandir normas de higiene destinadas a limitar la presencia de enfermedades infectocontagiosas; además, se dio paso a la higienización de las ciudades mediante la provisión de agua potable y servicio de alcantarillado en las ciudades importantes ${ }^{12}$. Se

12 En 1877 se empezaron a construir los primeros acueductos y alcantarillados, cuyos sistemas se desarrollan completamente a inicios del siglo XX y hacia 1886 efectuaron programas de control y erradicación de enfermedades como el paludismo, la viruela, la tuberculosis y la fiebre amarilla, que estuvieron relacionadas con la expansión del capitalismo y la prioritaria necesidad de recuperar y reproducir la fuerza laboral.

En el antiguo sistema político soberano existía entre el súbdito y el soberano una serie de relaciones jurídicas y económicas que comprometían y hasta obligaban al rey y sus instituciones a brindar protección y seguridad a los súbditos; pero, en cierto sentido como lo advierte Foucault, esa protección era exterior. El súbdito podía pedir a su soberano que lo protegiera contra el enemigo externo, pero en el caso del liberalismo las cosas cambiaron; lo que debe asegurarse ya no es únicamente la suerte de una protección exterior al individuo, pues el liberalismo participa en el arbitramento de la libertad y la seguridad de los individuos en torno a un imaginario que se va a imponer en el siglo XIX y es la noción de peligro, el miedo al peligro y afectación del cuerpo. El liberalismo es un arte de gobernar que en lo fundamental manipula los intereses de los ciudadanos y al mismo tiempo se constituye en el administrador de los peligros, en el propagador de la información sobre el peligro y en el administrador que brinda las respuestas de seguridad y libertad para que tanto individuos como colectividades se expongan lo menos posible a los peligros.

"Como es natural, esto entraña una serie de consecuencias. Puede decirse que, después de todo, la divisa del liberalismo es "vivir peligrosamente". "Vivir peligrosamente", esto es, que los individuos se vean a perpetuidad en una situación de peligro o, mejor, estén condicionados a experimentar su situación, su vida, su presente, su futuro, como portadores del peligro; y esa especie de estímulo del peligro va a ser una de las principales implicaciones del

se reglamentó la salud pública con la Junta Central de higiene en lo concerniente al manejo de aguas y medidas preventivas de enfermedades epidémicas. 
liberalismo. En efecto, en el siglo XIX aparece toda una educación del peligro, toda una cultura del peligro que es muy diferente de esos grandes sueños o esas grandes amenazas apocalípticas como la peste, la muerte, la guerra, de las que se alimentaba la imaginación política y cosmológica de la Edad Media e incluso del siglo XVII. Desaparición de los jinetes del Apocalipsis y, al contrario aparición, surgimiento, invasión de los peligros cotidianos, peligros cotidianos perpetuamente animados, reactualizados, puestos en circulación, entonces, por lo que podríamos llamar la cultura del peligro en el siglo XIX y que tiene toda una serie de aspectos. Tómense, por ejemplo (...) todas las campañas relacionadas con la enfermedad y la higiene; miren también todo lo que pasa en torno a la sexualidad y del miedo a la degeneración: (FOUCAULT: 1999: 297-300)

Más aún, con el cambio de concepción de la enfermedad entre el s. XVIII y XIX, también cambió el imaginario respecto a la pobreza. Antes la pobreza se asumía como la victimización de muchas personas que recibían caridad fraterna, necesaria para ganar indulgencias y la bendición del cielo; luego, la pobreza dejó de ser vista como una eventualidad del individuo, objeto de la caridad cristiana, para convertirse en un estorbo, en una anomalía o disfunción de la sociedad, lo cual es objeto de continua corrección por parte del Estado. Este ya no se ocupó de cuidar a los pobres como antes, sino más bien procuró integrar a toda esta población a la vida productiva; se trataba de convertir al "inválido" en persona "válida", al ocioso en persona útil, amante del trabajo. Así pues, instituciones como los hospicios cambiaron radicalmente su configuración, de ser sitios destinados a albergar jóvenes desprotegidos, pasó a ser un centro de enseñanza de artes y oficios, donde clasificaban y resocializaban a los mendigos y jóvenes de la calle para, finalmente, devolverlos a la sociedad como personas útiles, capaces de trabajar y reactivar la producción económica de la nación. Los seis censos que se organizaron durante el siglo XIX estuvieron orientados a brindar información sobre la recuperación de la mano de obra laboralmente activa ${ }^{13}$. Degeneración del individuo, de la familia, de la raza, de la especie humana. Por último, vemos en todas partes esa estimulación del temor al peligro que en cierto modo es la condición, el correlato psicológico y cultural interno del liberalismo. No hay liberalismo sin cultura del peligro. (FOUCAULT: 2008: 87)

La otra institución que también cambió fue el hospital; de ser un lugar para hospedar gente inválida, pasó a ser un centro de investigación y de enseñanza, un lugar de paso para la cura y recuperación de los enfermos que debían retornar a la vida productiva y útil, en beneficio del Estado. Entonces, los hospitales no sólo debían tener cuartos y salas para atender enfermos, sino también espacios abiertos, amplios, salones de clase suficientes para implementar una escuela de medicina que incluyera el jardín botánico, el gabinete de zoología y el observatorio astronómico. El hospital fue diseñado como una máquina de vigilancia y curación, pues su objetivo además de restablecer la salud a los enfermos, debía garantizar el seguimiento de la recuperación de las facultades corporales hasta la inserción en la vida laboral útil a la economía nacional. (CASTRO-GÓMEZ: 2004: 163)

Con respecto a los esclavos negros $e$ indios se cambió el concepto. Con los Austria se había generado la mala política de permitir que los criollos miraran a los negros e indios como si fueran propiedad privada, entonces no se preocupaban por su educación, por su cualificación en oficios, menos por su salud y buenos cuidados de higiene. Con los

13 El censo de 1870 presenta una sobreestimación de la proporción de población menor de 20 años y una subestimación de la población adulta, que se articulaba con los objetivos tributarios de enumeración de la población de la época. 
Borbones esta política cambió y fue necesario que el Estado, poco a poco, asumiera la responsabilidad social de cuidar la salud de esta población, pues bajo este principio se asumió que:

A mayor cantidad de individuos sanos, mayor será la tasa de crecimiento poblacional y "mayores serán las ganancias que deriven de su trabajo". Y si el segmento de la población que sostiene la economía es el de los indios, negros y mestizos, entonces el deber del Estado es velar por su salud y proporcionar los medios adecuados para curarlos cuando se enferman. (CASTROGÓMEZ: 2004: 167)

Dentro de las doctrinas fisiocráticas de los franceses se difundió la idea que la riqueza de una nación la constituye la producción de recursos naturales, producto de la explotación de las tierras y la propiedad se debe entender como consecuencia del trabajo. Este argumento pudo legitimar la apropiación de tierras habitadas por otros que no las trabajaran. El "cultivar" la tierra fue atributo de la sociedad civilizada que aseguraba su sustento alimenticio y el gobierno era quien debía proteger esa propiedad; éstas pronto se convirtieron en principio y base para las nuevas políticas del Rey de España y sus ministros, como Campomanes, Floridablanca, Aranda y Roda. Por esta razón, se introdujeron reformas que le dieron prioridad al desarrollo de la medicina, la estadística poblacional, la historia natural, la geografía física y los viajes de exploración.

Bajo las reformas borbónicas, las ciencias de la salud se desarrollaron y se incorporó la racionalización matemática, física y química, como componentes fundamentales de su evolución. Bajo la influencia de los adelantos de Newton y otros científicos se fue imponiendo en los círculos intelectuales una visión mecanicista del mundo y de la naturaleza que rompió con los esquemas del neoplatonismo ${ }^{14}$ que habían

14 Al ser considerado el cuerpo como cárcel del alma y oprobio por los pecados de la carne. frenado los avances sobre los estudios del cuerpo, y produjo fuertes influencias sobre la enseñanza, los nuevos planes y programas de estudio en las facultades de medicina ${ }^{15}$.

Las enseñanzas de Mutis sobre Newton era su idea de que el método correcto en filosofía natural conducía tanto a Dios como al desarrollo o progreso del hombre. Uno de los textos que Mutis presentó en la Universidad del Rosario, donde la filosofía natural se presenta como fundamento para la fe y la religión, fue: "Elementos de filosofía natural que contienen los principios de la física, demostrados por las matemáticas y confirmado con observaciones y experiencias: Dispuestos para instruir la juventud en la filosofía newtoniana". Pero Mutis no fue la única fuente de la mecánica moderna en América, pues a lo largo del XVIII las colonias recibieron publicaciones europeas que incluían las obras más representativas del momento; Sin embargo no sería sino hasta 1820, cuando Félix Restrepo publicó sus lecciones de física, que la gente de la Nueva Granada tuvo acceso a un texto en lengua castellana para el estudio de la ciencia newtoniana. (NIETO OLARTE: 2000: 244-245)

En su ensayo de 1801 titulado: "Estado de la medicina y la cirugía en el Nuevo Reino de Granada en el siglo XVIII y medios para remediar su lamentable atraso, José Celestino Mutis afirma que

15 En la Edad Media la cirugía estaba en sus albores por la falta de conocimientos anatómicos. En la antigüedad se hacían muchas operaciones y suponemos que una de las primeras fue la trepanación del cráneo, que se practicaba en la mayoría de las culturas arcaicas. La cirugía ortopédica y traumatológica fue una necesidad para remediar las enfermedades producidas por los traumatismos. Una de las operaciones más importantes en el mundo antiguo fue la "talla perineal”, utilizada para extraer cálculos localizados en la vejiga o en la porción inicial de la uretra. Desde la época hipocrática se habló de ella; en "el juramento" está proscrita la intervención, debido probablemente a la alta moralidad. En la obra de Celso (año 30 DC) están descritas muchas operaciones, entre ellas la "talla" vesical. DE ZUBIRÍA, Roberto. La medicina en el Descubrimiento de América. Instituto Colombiano de Cultura Hispánica. Bogotá. 1992. p. 89 
Todas las naciones bárbaras, aunque privadas de las luces de las ciencias útiles, conocen la necesidad de una medicina empírica, que ejercen casi por instinto socorriendo a sus semejantes; pero contentarse con tales socorros una nación civilizada y culta desde su conquista, sería confundirse con aquéllas apartándose del común consentimiento de todo el mundo racional. (MUTIS, J. C.: En: NIETO, M. 2000: 35)

Sólo se dieron ingentes proyectos para reformar en las universidades los programas de medicina, pues se pensó que mejor era traer los médicos formados desde España. A los intentos como el de Francisco Moreno (1789), quien valoraba la necesidad de fundar una universidad pública con la idea de reemplazar la dominación religiosa y aristotélica de los colegios, se sumaba la de un plan de estudios elaborado por el virrey Caballero y Góngora, pero con fuerte influencia del sabio Mutis quien había pensado en la posibilidad de un nuevo programa para profesionalizar la medicina, en él se incluiría química, botánica, dibujo, anatomía y matemáticas; además, se planteó la necesidad de un nuevo anfiteatro, más higiénico, para las disecciones de cadáveres. Pero ninguno de esos proyectos tuvo éxito sino hasta 1801 cuando el mismo Rey aprobó y ordenó el restablecimiento del currículum de las facultades de medicina para el nuevo reino. Estos planes propuestos por Mutis se implementaron en la Nueva Granada entre 1802 y 1805; Mutis afirmaba que un médico competente debía saber los secretos que confiere el conocimiento de la naturaleza y sus leyes y según él "sería imposible llamarse médico el que careciera de la suficiente instrucción de las ciencias matemáticas, física experimental, botánica y química”. (NIETO: 2000: 251)

\section{A MODO DE CONCLUSIONES}

El cuerpo humano se estudió desde la mecánica y había que interpretar las leyes de los distintos sistemas y órganos con un rigor tal que aseguró la incorporación paulatina de los aparatos de medición, instrumentos que permitieron medir no sólo el comportamiento de cada uno de los órganos y sistemas, sino la frecuencia y sintomatología de las enfermedades. Además, se incorporaron las estadísticas poblacionales ${ }^{16}$ como una herramienta fundamental para cuantificar los problemas de salud por regiones y poder controlar el desplazamiento y propagación de las enfermedades virales. Nació así el interés por la aplicación de la estadística sobre las ciencias de la salud como componente fundamental del control poblacional ${ }^{\mathrm{O} 17}$, ciencias necesarias para el buen gobierno.

Así mismo, con la incorporación de los nuevos conceptos científicos sobre las ciencias de la salud, se profesionalizó el ejercicio de médicos, cirujanos y boticarios, desde las Reformas Borbónicas se impartieron instrucciones, leyes y reglamentos que prohibieron el ejercicio médico a personas que no contaran con la "debida licencia para curar" (RUíZ: 1946). El estudio del cuerpo humano se empezó a desmembrar, ya no era "científico" verlo desde la integralidad del ser, sino desde la parcelación de los conocimientos y los saberes.

Como si se tratara de una alegoría de las estrategias modernas, la formación replica los mecanismos de control y demarcación espacial sobre los cuerpos, los enfermos y las pautas de enseñanza. Analizando de esta manera podemos entender cómo desde un comienzo se

16 En realidad muchos estudios advierten la inestabilidad en los datos poblacionales en la Colombia del siglo XIX sin llegar a un consenso, debido a la falta de información confiable y completa, además se presentaban muchos errores en los censos de población debido principalmente a las condiciones de guerra y de inestabilidad política.

17 El inicio de la demografía demarcó las características de la población, sus recursos humanos y materiales, la estratificación laboral, las prioridades y necesidades de salud, con lo cual se sistematizó el procedimiento de carácter público con cobertura del $100 \%$ de la población, dependiendo de la gestión de un poder controlado por el gobierno. 
asumió la educación de las enfermeras desde un paradigma positivista, en donde se considera la enfermedad como un estado individual, cerrado, limitante, discontinuo, descontextualizado y sin historia, en el que es más importante el control de la enfermedad y no el cuidado de la salud. Al respecto Riveros menciona:

La ciencia de la enfermería deberá experimentar, descubrir, medir, observar $e$ inventar teorías que expliquen el ¿cómo? $Y$ el ¿por qué? de los fenómenos de enfermería $e$ inventar técnicas $y$ herramientas, proponer y disponer, hacer hipótesis y ensayar, crear conjeturas, refutar, confirmar o no confirmar, separar lo verdadero de lo falso, lo que tiene sentido de lo que no lo tiene. Así diremos cómo llegar a donde queremos y en definitiva cómo llegar a donde queremos llegar y, lo más importante cómo hacer cuanto queremos hacer. Será el impulso el que moverá la ciencia de enfermería para seguir avanzando (RIVEROS: 1982: 82).

Ante todo es importante recordar el papel central que jugó la medicina y el inicio de la enfermería como disciplina entre los siglos XVIII al XIX y su relación con la presencia europea en América. De manera similar al papel que desempeñaron los sacerdotes y misioneros que cristianizaban a los nativos y civilizaban a los salvajes para salvar sus almas, el médico tenía la misión de salvar el cuerpo. Durante el siglo XVIII los médicos desarrollaron una fuerte autoridad moral y con frecuencia, tanto médicos como religiosas enfermeras se convertían en los agentes centrales de un control estatal configurado desde la religión y la fe en Cristo. Y así como Foucault ha señalado, durante el siglo XVIII la salud fue uno de los objetivos esenciales del poder político, no sólo por el interés de mantener la fuerza laboral activa, sino para manejar y controlar las fuerzas del imperio como un todo, desde su fuerza productiva y económica hasta la enunciación de los principios civilizatorios en todo el territorio colonizado.
A finales del XVIII y durante el XIX, la perspectiva de la medicina cambió y la mayoría de médicos y enfermeras de la época coincidieron en explicar las enfermedades como consecuencia de las bajas costumbres y malos comportamientos en materia de higiene. Con frecuencia muchas enfermedades eran directamente consecuencia del contacto con plagas, de falta de disciplina - limpieza de las gentes. Las enfermeras se convirtieron en protectoras del cuerpo enfermo, vigilantes constantes de los pacientes, vinculadas al cuidado afectivo de las personas que necesitaban palabras de consuelo. En un comienzo la medicina no tenía un estatus social demasiado importante y la enfermería era inexistente como disciplina. El interés del Estado por promover y mejorar la educación médica llegaría con las Reformas Borbónicas de la Ilustración; tales reformas, tanto en las universidades como en los hospitales, reflejaron las políticas de fortalecimiento de la administración estatal para reducir el poder administrativo del clero. A pesar de haber expulsado a los jesuitas en 1767, desde el gobierno central se constataba que las órdenes religiosas todavía seguían con mucho poder gracias al control sobre la educación y la salud. Poder que en la actualidad aún mantiene algún remanente que se evidencia no sólo por la fuerte presencia de entidades de educación y de salud lideradas por órdenes religiosas, sino además por la fuerte influencia de la iglesia católica en la toma de decisiones $y$ deliberaciones en el ámbito legislativo en cuestiones de salud pública o sexualidad, en muchas ocasiones desconociendo dispositivos $e$ injerencias que competen a la mujer y a su proceso reproductivo.

\section{BIBLIOGRAFÍA}

ACSADI, G. Y. (1970). Et al. History of human life span and mortality. Budapest, Hungría: Hungarian Academic Society.

CASTRILLÓN, M.C. (1985). La formación Universitaria de enfermeras en Colombia. 
1937-1980. Tesis de maestría en educación: sociología de la educación. Medellín, Colombia: Universidad de Antioquia.

CASTRO, S. (2004). La hybris del punto cero: ciencia, raza e ilustración en la Nueva Granada (1750-1816). Bogotá, Colombia: Pontificia Universidad Javeriana / Instituto Pensar.

CLEMENT, J. P. (1983). El Nacimiento de la Higiene Urbana en la América Española del Siglo XVIII. Revista de Indias, (49)

CROSBY, A. W. Jr. (1972). The Columbian Exchange: Biological and Cultural Consequences of 1492. Westport, EE.UU.: Greenwood Press

CUETO, M. (2004). El valor de la salud: historia de la Organización Panamericana de la Salud. OMS

CUETOS, M. (1996). Salud, cultura y Sociedad en América Latina: Nuevas Perspectivas históricas. Lima, Perú: Instituto de Estudios Peruanos / Organización Panamericana de la Salud.

DE ZUBIRÍA, R. (1992). La medicina en el Descubrimiento de América. Bogotá, Colombia: Instituto Colombiano de Cultura Hispánica.

DONAHUE, M. P. (1985). Historia de la enfermería. Barcelona, España: Doyma.

FEE, E. (1993). Public Health, Past and Present: A Shared Social Vision. En G. ROSEN. A History of Public Health. Baltimore, EE.UU.: Johns Hopkins Univ.

FOUCAULT, M. (1992). Genealogía del poder (A. Tzveibely, Trad.). Madrid, España: Endimión.

FOUCAULT, M. (1990). La vida de los hombres infames. Genealogía del poder. Madrid, España: Ediciones La Piqueta.

Foucault, M. (1999) Les Anormaux. Cours au Collège de France, 1974-1975, clase del 19 de marzo de 1975. Editor Marchetti, V \& Salomoni, A. Paris, Francia: Gallimard/Seuil, col Hautes Études
FOUCAULT, M. (2008). Nacimiento de la biopolítica. Buenos Aires, Argentina: FCE.

FOUCAULT, M. (1980). The politics of health in the eighteenth century. En Power Knowledge: selected interviews and the other writings 19721977. London, England: The Harvester Press.

HERNÁNDEZ, J. (1995). Historia de la enfermería. Un análisis histórico de los cuidados de enfermería. Interamericana. Madrid, España: McGraw-Hill.

MARRINER, \& TOMEY, A. (1994) Modelos y Teorías en Enfermería. (3ra Ed). Madrid, España: Mosby/Doyma Libros.

MUTIS, J. C. (3 de junio de 1801). Estado de la medicina y la cirugía en el Nuevo Reino de Granada en el siglo XVIII y medios para remediar su lamentable atraso. Santafé. En M. NIETO. (2000) Remedios para el Nuevo Mundo: historia natural y la apropiación del Nuevo Mundo. Bogotá, Colombia: Instituto Colombiano de Antropología e Historia - ICAHN.

NIETO, M. (2000). Remedios para el Nuevo Mundo: historia natural y la apropiación del Nuevo Mundo. Bogotá, Colombia: Instituto Colombiano de Antropología e Historia - ICAHN.

QUEVEDO, E. (1993). Institucionalización de la medicina en Colombia 1492-1860: antecedentes de un proceso. Historia social de la ciencia en Colombia. Tomo VII. Bogotá, Colombia: Conciencias.

RIVEROS, H. (1982). El método científico aplicado a las ciencias experimentales. Ciudad de México, México: Trillas.

RUÍZ, A. (1946) La medicina en la legislación medioeval española. Buenos Aires, Argentina: El Ateneo.

SHYOCK, R. H. (1959). The history of nursing: an interpretation of the social and medical factors involved. Filadelfia, EE.UU.: W.B. Saunders Co 